\title{
Genetic silencing of Nrf2 enhances X-ROS in dysferlin-deficient muscle
}

\author{
Ponvijay Kombairaju ${ }^{1+}$, Jaclyn P. Kerr ${ }^{2+}$, Joseph A. Roche ${ }^{2+}$, Stephen J. P. Pratt ${ }^{3}$, Richard M. Lovering ${ }^{3}$, \\ Thomas E. Sussan ${ }^{1}$, Jung-Hyun Kim ${ }^{1}$, Guoli Shi ${ }^{4}$, Shyam Biswal ${ }^{1 *}$ and Christopher W. Ward ${ }^{4 *}$ \\ ${ }^{1}$ Department of Environmental Health Sciences, Bloomberg School of Public Health, Johns Hopkins University, Baltimore, MD, USA \\ 2 Department of Healthcare Sciences, Eugene Applebaum College of Pharmacy and Health Sciences, Wayne State University, Detroit, MI, USA \\ ${ }^{3}$ Department of Orthopaedics, University of Maryland School of Medicine, Baltimore, MD, USA \\ ${ }^{4}$ Department of Organizational Systems and Adult Health, University of Maryland School of Nursing, Baltimore, MD, USA
}

\section{Edited by:}

Aikaterini

Kontrogianni-Konstantopoulos,

University of Maryland, USA

Reviewed by:

Sakthivel Sadayappan, Loyola

University Chicago, USA

Ranganath Mamidi, Case Western

Reserve University, USA

\section{*Correspondence:}

Shyam Biswal, Department of

Environmental Health Sciences,

Bloomberg School of Public Health,

Johns Hopkins University, 615 N.

Wolfe Street, Baltimore, MD 21205,

USA

e-mail: sbiswal@jhsph.edu;

Christopher W. Ward, Department

of Organizational Systems and Adult

Health, University of Maryland

School of Nursing, 655 W. Lombard

Street, Baltimore, MD 21201, USA

e-mail:ward@son.umaryland.edu

${ }^{+}$These authors have contributed

equally to this work.
Oxidative stress is a critical disease modifier in the muscular dystrophies. Recently, we discovered a pathway by which mechanical stretch activates NADPH Oxidase 2 (Nox2) dependent ROS generation (X-ROS). Our work in dystrophic skeletal muscle revealed that X-ROS is excessive in dystrophin-deficient $(m d x)$ skeletal muscle and contributes to muscle injury susceptibility, a hallmark of the dystrophic process. We also observed widespread alterations in the expression of genes associated with the X-ROS pathway and redox homeostasis in muscles from both Duchenne muscular dystrophy patients and $m d x$ mice. As nuclear factor erythroid 2-related factor 2 (Nrf2) plays an essential role in the transcriptional regulation of genes involved in redox homeostasis, we hypothesized that Nrf2 deficiency may contribute to enhanced X-ROS signaling by reducing redox buffering. To directly test the effect of diminished Nrf2 activity, Nrf2 was genetically silenced in the $A / J$ model of dysferlinopathy-a model with a mild histopathologic and functional phenotype. Nrf2-deficient A/J mice exhibited significant muscle-specific functional deficits, histopathologic abnormalities, and dramatically enhanced X-ROS compared to control A/J and WT mice, both with functional Nrf2. Having identified that reduced Nrf2 activity is a negative disease modifier, we propose that strategies targeting Nrf2 activation may address the generalized reduction in redox homeostasis to halt or slow dystrophic progression.

Keywords: Nrf2, X-ROS, ROS, dysferlin, dystrophy

\section{INTRODUCTION}

In dystrophin-deficient heart and skeletal muscle, we recently identified that NADPH oxidase 2 (Nox2) dependent reactive oxygen species (ROS) production (i.e., X-ROS) is dramatically enhanced with stretch or contraction and contributes to the enhanced susceptibility to injury (Prosser et al., 2011; Khairallah et al., 2012). Furthermore, we demonstrated that this enhanced XROS is temporally progressive as X-ROS is virtually non-existent in young $(\sim 8$ week $)$ and in great excess in mature adult $(\sim 7$ month) dystrophic animals.

Limb girdle muscular dystrophy type 2B (LGMD2B), Miyoshi myopathy, and distal myopathy are progressive, late-onset dystrophies linked to mutations in, or loss of, the dysferlin protein that present clinically as weakness in the proximal or distal muscles with elevated serum creatine kinase (CK) and muscle degeneration (Nigro, 2003; Klinge et al., 2008; Amato and Brown, 2011). We reported that aged ( $\sim 12$ month) dysferlin-deficient murine muscle also exhibits amplified X-ROS signaling (Prosser et al., 2013), a finding congruent with the recent reports suggesting that oxidative stress underscores the late onset and temporal progression of dysferlinopathy (Terrill et al., 2013). Despite these findings, it is unclear what manifests the age-dependent increase in X-ROS in these dystrophic models.

Within the healthy muscle cell, ROS are generated as both a by-product of metabolism and as effectors of signaling cascades. Excess ROS is counteracted by proteins that promote reduction-oxidation (i.e., redox) chemistry under normal conditions. Our recent work identified a down-regulation in the transcriptional profile of redox related genes in murine adult dystrophin-deficient $(m d x)$ tibialis anterior muscle (Khairallah et al., 2012), suggesting that a decrease in redox related proteins may induce a shift to a more oxidized environment and drive dysfunction in dystrophic muscle.

Nuclear factor erythroid 2-related factor 2 (Nrf2) is a transcription factor ubiquitously expressed in most tissues, but most abundantly in kidney, striated muscle, and lung. Nrf2 is bound to Kelch like-ECH-associated protein 1 (Keap1) in the cytosol. In response to oxidative stress, the Nrf2-Keap1 interaction is disrupted and Nrf2 translocates into the nucleus where it activates the Antioxidant Response Element (ARE) which transcriptionally activates many antioxidative genes. In this role, Nrf2 activity has been demonstrated to be an important disease modifier in many 
oxidative/inflammatory diseases, such as asthma, sepsis, cerebral hemorrhage, and pulmonary fibrosis, where decreased Nrf2 activity exacerbates disease progression (Cho et al., 2004; Rangasamy et al., 2005; Thimmulappa et al., 2006; Wang et al., 2007).

As we recently identified amplified X-ROS signaling in aged dysferlin-deficient A/J mice (Prosser et al., 2013) and others have now reported a temporal progression in muscle oxidation in dysferlin-deficient muscle (Terrill et al., 2013), we sought to directly test the hypothesis that a decrease in Nrf2 activity could serve as a disease modifier in dystrophic muscle. To this end we genetically silenced Nrf2 in the A/J mouse model of dysferlinopathy. We chose this model as it is considered a relatively weak model of dysferlinopathy due to its lack of significant functional deficits and mild, late onset, histological presentation (Von der Hagen et al., 2005; Kobayashi et al., 2010; Gayathri et al., 2011; Grounds and Shavlakadze, 2011; Kobayashi et al., 2011; Terrill et al., 2013). Examination of A/J-Nrf2 ${ }^{-/-}$muscle at 12 months of age revealed a dramatic enhancement in X-ROS, significant decreases in muscle function, and histological evidence of myopathy. Taken together, these results support decreased Nrf2 activity as a disease modifier in dysferlinopathy.

\section{MATERIALS AND METHODS \\ MICE}

Dysferlin-null A/J mice were obtained from Jackson Laboratories and bred in our facility. A mouse model of dysferlinopathy with ablated Nrf2 (A/J-Nrf2-/-) was obtained by backcrossing $\mathrm{Nrf2}^{-/-}$mice (C57BL/6J background) 7 times with A/J mice. All experimental protocols conducted on the mice were performed in accordance with NIH guidelines and were approved by the Johns Hopkins University and University of Maryland, Baltimore Animal Care and Use Committees.

\section{ISOLATION OF FLEXOR DIGITORIS BREVIS (FDB) MYOFIBERS}

After euthanasia by $\mathrm{CO}_{2}$ inhalation, the FDB muscle was harvested bilaterally and incubated in Dulbecco's Modified Eagle's Medium (DMEM; Life Technologies, Grand Island, NY, USA) with $1 \mu \mathrm{l} / \mathrm{ml}$ gentamicin and $4 \mathrm{mg} / \mathrm{ml}$ collagenase A (Roche Applied Science, Indianapolis, IN, USA) for up to $3 \mathrm{~h}$ as previously described (Ziman et al., 2010; Dorsey et al., 2012). Single intact myofibers were then isolated by gentle trituration.

\section{MYOFIBER ATTACHMENT AND STRETCH}

All experiments were performed as described (Khairallah et al., 2012). In brief, we used a custom rotating glass-bottom chamber (Four-hour Day Foundation, Towson, MD, USA) equipped with bath perfusion and mounted on Zeiss Radiance fluorescent laser scanning confocal attached to an Olympus IX-70 inverted microscope (Olympus Corp., Centre Valley, PA, USA). A highsensitivity force transducer (KG7) and length controller (World Precision Instruments, Sarasota, FL, USA) were mounted on folded motorized micromanipulators (Siskiyou, Grants Pass, OR, USA). A single FDB fiber was attached to both the force transducer and the length controller using micro-tweezers coated with the biological adhesive, MyoTak (Ionoptix, Milton, MA, USA). Using a high-speed video sarcomere length system (HSVL; Aurora Scientific, Aurora, Ontario, Canada), initial sarcomere length and sarcomere length following passive stretch were monitored. To induce $\mathrm{X}-\mathrm{ROS}, \mathrm{FDB}$ fibers were challenged with a brief $5 \mathrm{~s}$ passive stretch (10\% sarcomere length).

\section{REACTIVE OXYGEN SPECIES (ROS) MEASUREMENTS}

ROS was measured as previously described (Prosser et al., 2011) using 6-carboxy- $2^{\prime}, 7^{\prime}$-dichlorodihydrofluorescein diacetate (DCFH-DA, or DCF) (Invitrogen, Carlsbad, CA, USA) in dimethyl sulfoxide (DMSO). FDB fibers were suspended in HEPES-buffered Ringer's solution containing (in $\mathrm{mM}$ ): $140 \mathrm{NaCl}$, $4 \mathrm{KCl}, 1 \mathrm{MgSO}_{4}, 5 \mathrm{NaHCO}_{3}, 10$ glucose, 10 HEPES at $\mathrm{pH} 7.3$ and incubated with Ringer's solution containing DCFH-DA $(10 \mu \mathrm{M})$ for $30 \mathrm{~min}$ at room temperature $\left(22^{\circ} \mathrm{C}\right)$. DCFH-DA-loaded cells were imaged using confocal line-scanning microscopy at $2 \mathrm{~ms} /$ line with the lowest laser power possible that reported a stretch dependent ROS signal. DCFH-DA fluorescence signals were processed as previously described (Prosser et al., 2011).

\section{WESTERN BLOTTING}

Western blot analysis was performed as previously described (Dorsey et al., 2012). Briefly, $20 \mu \mathrm{g}$ of clarified muscle extract was subjected to SDS-PAGE, transferred to nitrocellulose membranes and blocked in a 5\% milk solution in PBS for $1 \mathrm{~h}$. The membrane was probed overnight with primary antibody at room temperature. The primary antibodies were anti- $\alpha$ tubulin (DM1A, 1:1000; Sigma-Aldrich), anti- $\beta$-tubulin (AA12.1, 1:1000, Developmental Studies Hybridoma Bank), anti-Glutubulin (1:1000, Millipore, Temecula, CA, USA), anti-gp91 $1^{\text {phox }}$ (1:1000, BD Transduction Laboratories, Lexington, KY, USA), and anti-GAPDH (1:4000, Millipore). Membranes were washed twice for $10 \mathrm{~min}$ in $5 \%$ milk solution at room temperature, then incubated with appropriate secondary antibody $(1: 10,000)$ for $1 \mathrm{~h}$ at room temperature and washed in a $0.5 \%$ Tween solution in PBS twice for $10 \mathrm{~min}$. Immunoblots were developed using SuperSignal PicoWest chemiluminescence (Pierce, Rockford, IL, USA) and were imaged and quantified with a SYNGENE GBox imaging system (GeneTools software). GAPDH served as a loading control.

\section{IN VIVO ASSESSMENT OF QUADRICEPS FORCE}

Functional assessment of the quadriceps muscle was performed in vivo as described (Pratt et al., 2012). Mice were deeply anesthetized with isoflurane and placed in a supine position on the apparatus. The thigh was stabilized and the ankle secured onto a lever arm with the rotational axis of the knee aligned with the axis of the stepper motor/torque sensor. The femoral nerve was stimulated via subcutaneous needle determined by a series of isometric twitches and by observing isolated knee extension in the anesthetized animal. Maximal torque was assessed as the mean of 3 successive (1 min apart) maximal tetanic contractions ( $1 \mathrm{~s}$ train, $0.2 \mu$ s sq pulses, $100 \mathrm{~Hz}$ ).

\section{IN VITRO MUSCLE CONTRACTILITY}

Muscle performance of the extensor digitorum longus (EDL) was assessed in vitro using methods described previously (Williams et al., 1998). In brief, single EDL muscles were surgically excised with ligatures at each tendon (5-0 silk suture) and mounted in an in vitro bath between a fixed post and force transducer (Aurora 
300B-LR) operated in isometric mode. The muscle was maintained in physiological saline solution (PSS; $\mathrm{pH} 7.6$ ) containing (in $\mathrm{mM}$ ) $119 \mathrm{NaCl}, 5 \mathrm{KCl}, 1 \mathrm{MgSO}_{4}, 5 \mathrm{NaHCO}_{3}, 1.25 \mathrm{CaCl}_{2}$, $1 \mathrm{KH}_{2} \mathrm{PO}_{4}, 10 \mathrm{HEPES}, 10$ dextrose, and maintained at $30^{\circ} \mathrm{C}$ under aeration with $95 \mathrm{O}_{2} / 5 \mathrm{CO}_{2}$ (\%) throughout the experiment. Resting tension and stimulation current were iteratively adjusted for each muscle to obtain optimal twitch force. During a 5 min equilibration, single twitches were elicited at every $30 \mathrm{~s}$ with electrical pulses $(0.2 \mathrm{~ms})$ via platinum electrodes running parallel to the muscle. Optimal resting tension was determined and isometric tension was evaluated by $250 \mathrm{~ms}$ trains of pulses delivered at $1,10,20,40,60,80,100,150 \mathrm{~Hz}$. After the experimental protocol, the muscle rested for $5 \mathrm{~min}$ at which time muscle length was determined with a digital micrometer, muscle was trimmed proximal to the suture connections, blotted and weighed. The cross-sectional area for each muscle was determined by dividing the mass of the muscle $(\mathrm{g})$ by the product of its length $\left(L_{0}, \mathrm{~mm}\right)$ and the density of muscle [1.06 g/ $\mathrm{cm}^{3}$; (Mendez and Keys, 1960)] and was expressed in square centimeters. Muscle output was then expressed as isometric tension $\left(\mathrm{g} / \mathrm{cm}^{2}\right)$ determined by dividing the tension ( $\mathrm{g}$ ) by the muscle cross-sectional area. Maximal torque was assessed as the mean of 3 successive ( 1 min apart) maximal tetanic contractions ( $1 \mathrm{~s}$ train, $0.2 \mu \mathrm{s}$ sq pulses, $100 \mathrm{~Hz}$ ).

\section{HISTOPATHOLOGY}

Quadriceps muscles were fixed in 10\% formalin and flash frozen. Cross-sections $(5 \mu \mathrm{m})$ were obtained from the mid-belly of the muscle. $\mathrm{H} \& \mathrm{E}$ staining was performed to qualitatively assess inflammatory cell infiltrate and centrally nucleated fibers (CNFs). Picrosirius red staining was used to assess collagen and fibrosis. Digital images $(20 \times$ magnification $)$ were obtained and the area of rectus femoris was calculated using ImageJ (National Institutes of Health, Bethesda, MD). CNFs were quantified from images $(100 \times$ magnification) taken at the lesion in the rectus femoris from each genotype. ImageJ was used to calculate the total area of fat accumulation (vacuolated area).

\section{IMMUNOHISTOCHEMISTRY OF OXIDIZED PHOSPHOLIPIDS}

Muscle sections of $5 \mu \mathrm{m}$ thickness were generated from formalin fixed quadriceps were stained with antibodies generated against oxidized phospholipids (oxPL) to assess oxPL and oxidative stress. Staining was done according to the manufacturer's protocol (Dako). Digital images $(20 \times$ magnification) were at the same location in the muscle from each genotype.

\section{STATISTICS}

Statistical comparisons were performed using Student's $t$-test or One-Way ANOVA (SigmaStat v3.1) with significance set $a$ priori to 0.05 .

\section{RESULTS}

\section{STRETCH-INDUCED ROS GENERATION IS EXAGGERATED IN THE Nrf2-SILENCED DYSFERLIN DEFICIENT MUSCLE}

We recently reported on X-ROS, a signaling pathway by which mechanical stretch elicits Nox2 ROS signaling in heart and skeletal muscle (Prosser et al., 2011; Khairallah et al., 2012). The microtubule (MT) cytoskeleton is the mechano-transduction element that transmits the strain of stretch or contraction to Nox2, and hence, is critical for the generation of X-ROS. We further identified excess X-ROS magnitude and enhanced XROS protein expression (i.e., MT and Nox2 protein subunits) in dystrophin-deficient heart and skeletal muscle. In each tissue, the increased magnitude of X-ROS contributed to dysfunctional ROS, alterations in calcium signaling, and injury susceptibility. Integral to this current work, we most recently identified enhanced X-ROS and increased X-ROS-related protein expression in the A/J model of dysferlinopathy (Prosser et al., 2013).

Here we used an identical approach to assess the rate of ROS production in single isolated FDB myofibers from A/J-Nrf2 ${ }^{-/-}$ mice loaded with DCF and challenged with an acute stretch of a $10 \%$ change in sarcomere length. In FDBs from 12-month dysferlin-deficient $\mathrm{A} / \mathrm{J}$ mice, we confirmed a significant increase in X-ROS compared to WT controls. We found that in dysferlindeficient FDBs with genetically silenced Nrf2, the X-ROS rate was significantly elevated above that seen in the dysferlin-deficient A/J (Figures 1A,B). This result suggests that a decrease in Nrf2 activity accelerated the temporal manifestation of X-ROS in the dysferlin-deficient A/J model.

Western blot analysis revealed that Nrf2 silencing in the $\mathrm{A} / \mathrm{J}$ resulted in the increased expression of X-ROS-related proteins, including $\alpha$ - and $\beta$-tubulin, glu-tubulin, and gp91 ${ }^{\text {phox }}$ (Figure 2A), consistent with the increased magnitude of X-ROS we demonstrated in this model. Importantly, the silencing of Nrf2 alone (i.e., Nrf2 $2^{-/}$) did not result in an increased expression of these proteins, indicating that Nrf2 silencing in the dystrophic $\left(\mathrm{A} / \mathrm{J}-\mathrm{Nrf} 2^{-/-}\right)$model drove this response (Figure 2B).

\section{MUSCLE FUNCTION AND QUALITY IS DECREASED IN THE Nrf2-SILENCED DYSFERLIN DEFICIENT MOUSE}

We have proposed that excessive X-ROS signaling is a proximal mechanism for the muscle damage and force deficits in dystrophic muscle. To assess the effect of Nrf2 silencing on the dysferlindeficient $\mathrm{A} / \mathrm{J}$, we first evaluated nerve-evoked muscle function

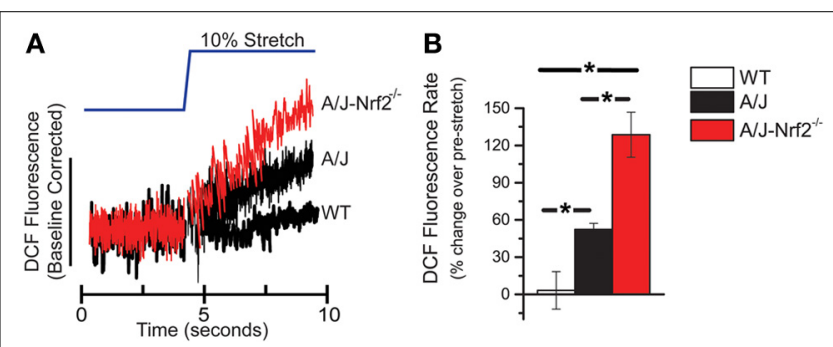

FIGURE 1 | X-ROS is enhanced in Nrf2 silenced dysferlin deficient muscle fibers. FDB fibers from WT $\left(n=3_{\text {animals }}, 8_{\text {fibers }}\right.$ ), dysferlin deficient $\mathrm{A} / \mathrm{J}\left(n=3_{\text {animals }}, 9_{\text {fibers }}\right)$, and Nrf2-silenced A/J ( $\left.n=3_{\text {animals }}, 11_{\text {fibers }}\right)$ were loaded with the fluorescent ROS probe DCF and attached with MyoTak between a high-sensitivity force transducer and length controller. The fibers were challenged with a brief $5 \mathrm{~s}$ passive stretch ( $10 \%$ sarcomere length) and DCF fluorescence signals (A) were processed as previously described (Prosser et al., 2011). The DCF fluorescent rate, expressed as a \% over the pre-stretch condition, revealed that WT stretch was not different from the pre-stretch condition, dysferlin deficient $\mathrm{A} / \mathrm{J}$ was significantly elevated over WT, and Nrf2 silenced A/J were elevated compared to each other genotype. The population averages are represented in the bar graph in (B). ${ }^{*} p<0.05$. 

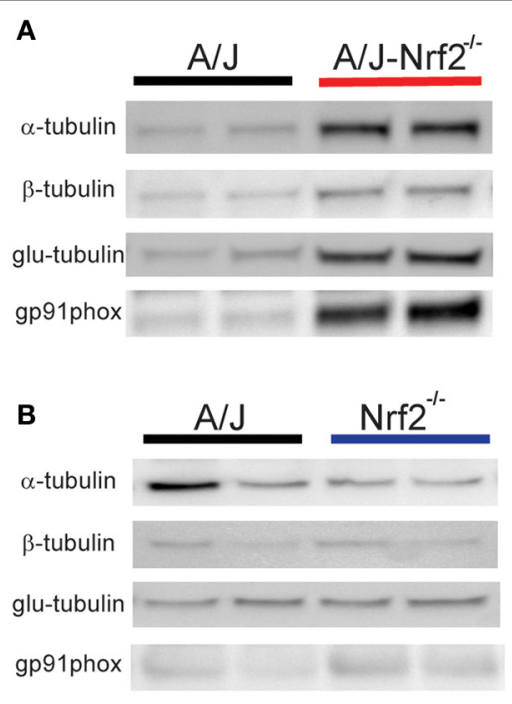

FIGURE 2 | X-ROS protein expression is elevated in Nrf2 silenced dysferlin deficient muscle. Western blot analysis of gastrocnemius muscle from 1 year old mice identified that X-ROS protein content is significantly
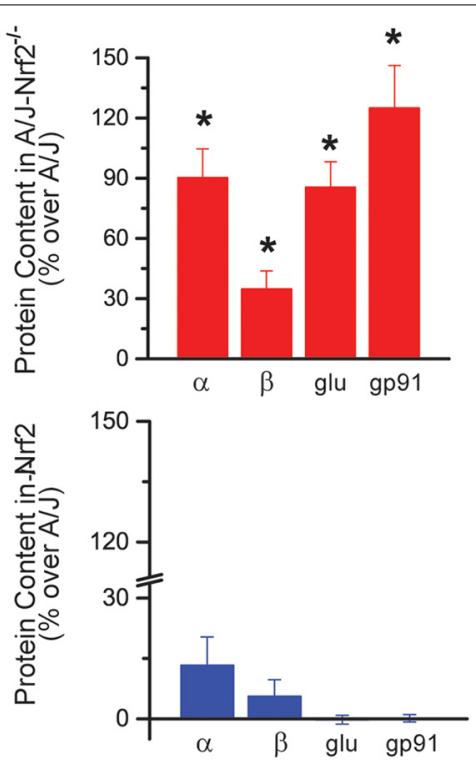

elevated in Nrf2 silenced A/J muscle (A) $(n=5)$ but not in Nrf2 silenced muscle (B) $(n=5)$. Percent changes in protein expression are demonstrated in the bar graphs to the right of both $(\mathbf{A}, \mathbf{B}) .{ }^{*} p<0.05$.
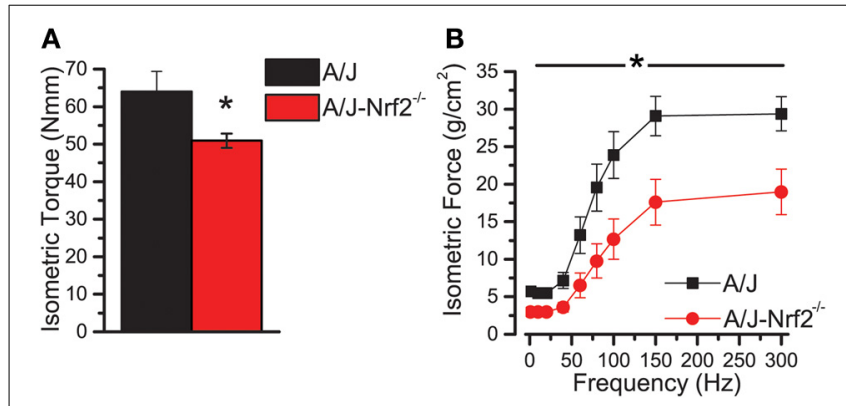

FIGURE 3 | Nrf2 silenced A/J muscle exhibits a loss-of-function phenotype. (A) In vivo assessments of isomeric quadriceps torque and (B) in vitro assessments of EDL contractility via the force vs. stimulation frequency relationship both revealed significant loss-of-function phenotypes in the Nrf2 silenced dysferlin deficit $\mathrm{A} / \mathrm{J}$ muscle. ${ }^{*} p<0.05$.

in vivo. Evaluation of quadriceps muscle function revealed a significant deficit in maximal isometric torque in the $\mathrm{A} / \mathrm{J}-\mathrm{Nrf} 2^{-/-}$ vs. the A/J (Figure 3A) despite no difference in bodyweight (27.2 \pm 2.1 vs. $28.4 \pm 1.9 \mathrm{~g}$ ). To assess muscle specific force production, we analyzed electrically evoked contractions in single EDL muscles in vitro. An examination of the force (normalized to the muscle cross-sectional area) vs. stimulation frequency relationship revealed a significant deficit in force producing capacity in the $\mathrm{A} / \mathrm{J}-\mathrm{Nrf} 2^{-/}-$(Figure 3B). Histological analysis of the quadriceps muscles provided insight for the deficits in muscle function following Nrf2 ablation, as A/J-Nrf2-/- mice exhibit enhanced degeneration compared to A/J mice (Figure 4). Furthermore, these muscles present with increased immune cell infiltrate (Figure 4A; top, right), fibrosis (Figure 4A; bottom, right), steatosis (fat accumulation), and a concomitant decrease in total myofiber area in cross-section (Figure 4B). Taken together

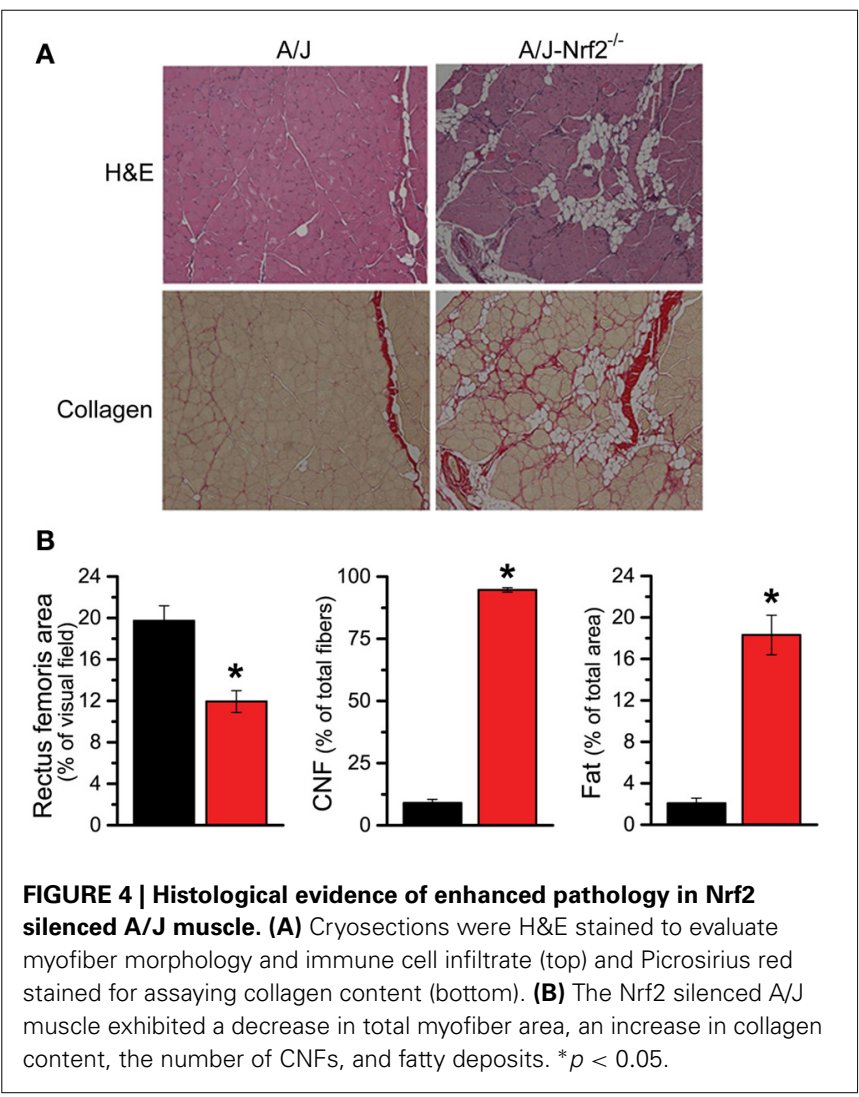

with the increase in the occurrence of CNFs and evidence of increased oxidative stress (Figure 5), we conclude that the A/J-Nrf2 $2^{-/}$mouse presents with a significantly enhanced dystrophic phenotype compared to age-matched $\mathrm{A} / \mathrm{J}$ mice. 


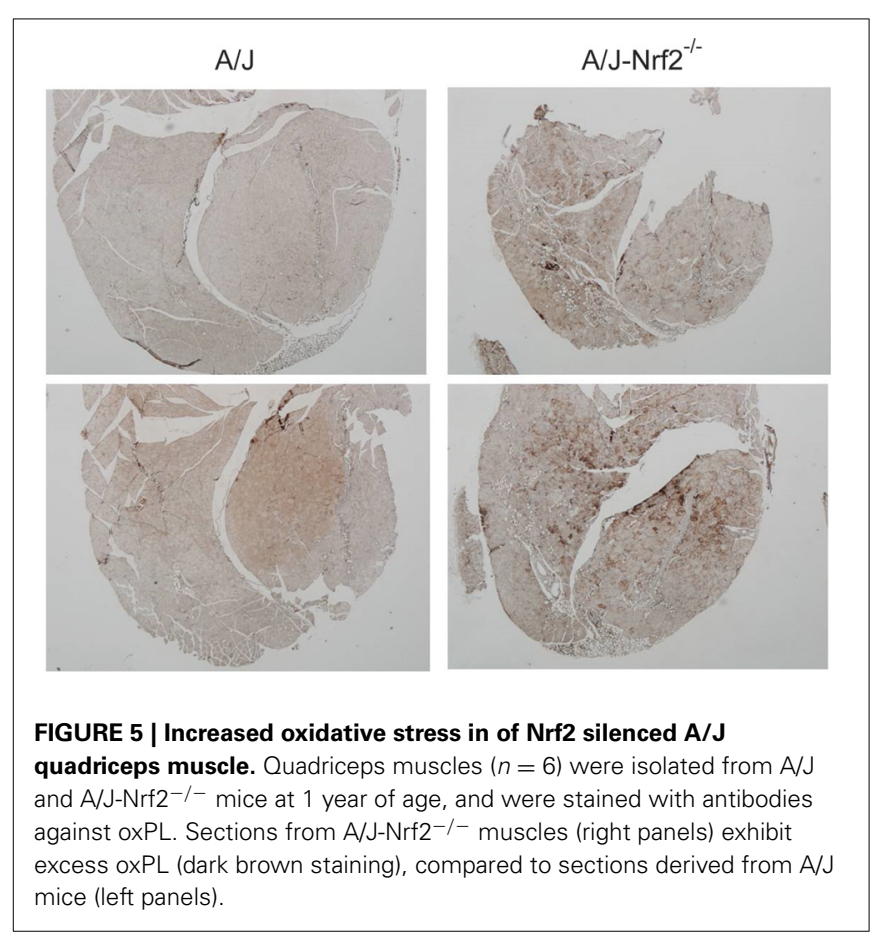

\section{DISCUSSION}

LGMD2B, Miyoshi myopathy, and distal myopathy are progressive dystrophies that present clinically as weakness in the proximal or distal muscles with elevated serum CK and muscle degeneration (Nigro, 2003; Klinge et al., 2008; Amato and Brown, 2011). These diseases are established as late-adult onset both clinically (Gordon et al., 1993; Klinge et al., 2008; Angelini et al., 2010, 2011; Gayathri et al., 2011) as well as in preclinical models (Turk et al., 2006; Nemoto et al., 2007; Ng et al., 2012). While these disorders have been linked to the mutation or ablation of the dysferlin gene (DYSF) (Illarioshkin et al., 2000; Vainzof et al., 2001; Nguyen et al., 2005; Cacciottolo et al., 2011), a consensus on the mechanistic basis of disease has not been reached.

Early functional studies in murine muscle (Bansal et al., 2003; Bansal and Campbell, 2004) implicated dysferlin as an integral component for rapid repair of the sarcolemma. However, more recent reports indicate that dysferlin is also involved in vesicle fusion, cellular adhesion, MT regulation and the stabilization of sarcolemmal/transverse-tubule $\mathrm{Ca}^{2+}$ homeostasis (Lennon et al., 2003; Covian-Nares et al., 2010; Sharma et al., 2010; Di Fulvio et al., 2011; De Morree et al., 2013; Kerr et al., 2013). Most recently, evidence points to an age-dependent enhancement in oxidative stress in dysferlin-deficient muscle (Prosser et al., 2013; Terrill et al., 2013) leading us to speculate that a progressive enhancement in oxidative stress may temporally associate with the late onset of muscle pathology seen in dysferlinopathy.

We previously identified a decrease in redox related genes in Dmd muscle (Khairallah et al., 2012), and have identified similar profiles from interrogating publically available microarray data from clinical biopsy samples of dysferlinopathic individuals (GEO repository; data not shown). Together, the increased lipid peroxidation in muscles of dysferlinopathy patients (Renjini et al., 2012), the progressive oxidation of muscle of dysferlin deficient A/J mice (Terrill et al., 2013), and the increase in X-ROS in dysferlin-deficient muscle (Prosser et al., 2013) all indirectly support a decline in Nrf2 activity as a factor in the onset and pathogenic progression of the disease. In further support of Nrf2's role, a decline in $\mathrm{Nrf} 2$ activity, increased oxidative stress and reduced antioxidant defense seem to be general phenomena in chronic diseases and aging (Malhotra et al., 2008; Safdar et al., 2010; Sykiotis and Bohmann, 2010), therefore it will be important to also evaluate the effect of Nrf2 silencing in the context of aging WT muscle, a comparison not made in this study.

Our sentinel measure of stretch activated X-ROS was previously shown to be elevated in the dysferlin-deficient $\mathrm{A} / \mathrm{J}$ mouse, and here we demonstrate a dramatic ( $>2$-fold) elevation in $\mathrm{X}$ ROS in A/J-Nrf2 $-/-$ muscle compared to the A/J (c.f. Figure 1). As discussed above, ROS production is countered by the endogenous cellular redox buffering systems such that a detectable increase in ROS production could be due to an increase in ROS production via more ROS producing sources (i.e., Nox2 or mitochondrial metabolism), a decrease in redox buffering, or a combination of both. Interestingly, the silencing of $\mathrm{Nrf} 2$ in the $\mathrm{A} / \mathrm{J}$ resulted in an increase in X-ROS proteins $(\alpha-, \beta$-tubulin and $\left.\mathrm{gp} 91^{\text {phox }}\right)$, which may suggest a more complex interplay of redox homeostasis and the transcriptional regulation of these $\mathrm{X}$ ROS-related proteins. Presently, pharmacological approaches that target single redox or ROS pathways (N-acetylcysteine, EGCG, Tocopherol) have shown mixed results in reducing the pathogenic progression of the muscular dystrophies (Scheuerbrandt, 2008), though combinatorial approaches may have better outcomes (Potgieter et al., 2011). In other diseases, genetic or pharmacological activation of $\mathrm{Nrf} 2$ has been shown to reduce oxidative and nitrosative stress and provide significant functional benefit (Thimmulappa et al., 2007; Sussan et al., 2009; Blake et al., 2010). Our results support a centralized role of Nrf2 deficiency in the pathogenesis of dysferlinopathy. We hypothesize that strategies targeting Nrf2 activation may ablate the core mechanistic hallmarks of dysferlinopathic progression (i.e., oxidative stress, inflammation, fibrosis, lipid accumulation). Further, as most muscular dystrophies share these mechanistic underpinnings, this approach, if successful, may have wide therapeutic applications.

\section{ACKNOWLEDGMENTS}

Shyam Biswal was partly supported by the Flight Attendant Medical Research Institute, National Cancer Institute lung spore grant P50 CA058184, R01 CA140492, and National Institute on Environmental Health Sciences center grant P50ES015903. Further support was provided by the NIH (R01-AR062554 to Christopher W. Ward, T32-AR07592 to Jaclyn P. Kerr, and R01AR059179 to Richard M. Lovering).

\section{REFERENCES}

Amato, A. A., and Brown, R. H. Jr. (2011). Dysferlinopathies. Handb. Clin. Neurol. 101, 111-118. doi: 10.1016/B978-0-08-045031-5.00007-4

Angelini, C., Nardetto, L., Borsato, C., Padoan, R., Fanin, M., Nascimbeni, A. C. et al. (2010). The clinical course of calpainopathy (LGMD2A) and dysferlinopathy (LGMD2B). Neurol. Res. 32, 41-46. doi: 10.1179/174313209X380847 
Angelini, C., Peterle, E., Gaiani, A., Bortolussi, L., and Borsato, C. (2011). Dysferlinopathy course and sportive activity: clues for possible treatment. Acta Myol. 30, 127-132. Available online at: http://www.ncbi.nlm.nih.gov/ pmc/articles/PMC3235880/

Bansal, D., and Campbell, K. P. (2004). Dysferlin and the plasma membrane repair in muscular dystrophy. Trends Cell Biol. 14, 206-213. doi: 10.1016/j.tcb.2004.03.001

Bansal, D., Miyake, K., Vogel, S. S., Groh, S., Chen, C. C., Williamson, R., et al. (2003). Defective membrane repair in dysferlin-deficient muscular dystrophy. Nature 423, 168-172. doi: 10.1038/nature01573

Blake, D., Singh, A., Kombairaju, P., Malhotra, D., Mariani, T., Tuder, R., et al. (2010). Deletion of Keapl in the lung attenuates acute cigarette smoke-induced oxidative stress and inflammation. Am. J. Respir. Cell Mol. Biol. 42, 524-536. doi: 10.1165/rcmb.2009-0054OC

Cacciottolo, M., Numitone, G., Aurino, S., Caserta, I. R., Fanin, M., Politano, L., et al. (2011). Muscular dystrophy with marked Dysferlin deficiency is consistently caused by primary dysferlin gene mutations. Eur. J. Hum. Genet. 19, 974-980. doi: 10.1038/ejhg.2011.70

Cho, H. Y., Reddy, S. P., Yamamoto, M., and Kleeberger, S. R. (2004). The transcription factor Nrf2 protects against pulmonary fibrosis. FASEB J. 18, 1258-1260. doi: 10.1096/fj.03-1127fje

Covian-Nares, J. F., Koushik, S. V., Puhl, H. L. III., and Vogel, S. S. (2010). Membrane wounding triggers ATP release and dysferlin-mediated intercellular calcium signaling. J. Cell Sci. 123, 1884-1893. doi: 10.1242/jcs.066084

De Morree, A., Flix, B., Bagaric, I., Wang, J., van den Boogaard, M., Grand Moursel, L., et al. (2013). Dysferlin regulates cell adhesion in human monocytes. J. Biol. Chem. 288, 14147-14157. doi: 10.1074/jbc.M112.448589

Di Fulvio, S., Azakir, B. A., Therrien, C., and Sinnreich, M. (2011). Dysferlin interacts with histone deacetylase 6 and increases alpha-tubulin acetylation. PLoS One 6:e28563. doi: 10.1371/journal.pone.0028563

Dorsey, S. G., Lovering, R. M., Renn, C. L., Leitch, C. C., Liu, X., Tallon, L. J., et al. (2012). Genetic deletion of trkB.T1 increases neuromuscular function. Am. J. Physiol. Cell Physiol. 302, C141-C153. doi: 10.1152/ajpcell.00469.2010

Gayathri, N., Alefia, R., Nalini, A., Yasha, T. C., Anita, M., Santosh, V., et al. (2011). Dysferlinopathy: spectrum of pathological changes in skeletal muscle tissue. Indian J. Pathol. Microbiol. 54, 350-354. doi: 10.4103/0377-4929.81636

Gordon, E., Pegoraro, E., and Hoffman, E. P. (1993). Limb-Girdle Muscular Dystrophy Overview, Seattle, WA: University of Washington Seattle.

Grounds, M. D., and Shavlakadze, T. (2011). Growing muscle has different sarcolemmal properties from adult muscle: a proposal with scientific and clinical implications: reasons to reassess skeletal muscle molecular dynamics, cellular responses and suitability of experimental models of muscle disord. Bioessays 33, 458-468. doi: 10.1002/bies.201000136

Illarioshkin, S. N., Ivanova-Smolenskaya, I. A., Greenberg, C. R., Nylen, E., Sukhorukov, V. S., Poleshchuk, V. V., et al. (2000). Identical dysferlin mutation in limb-girdle muscular dystrophy type 2B and distal myopathy. Neurology 55, 1931-1933. doi: 10.1212/WNL.55.12.1931

Kerr, J. P., Ziman, A. P., Mueller, A. L., Muriel, J. M., Kleinhans-Welte, E., Gumerson, J. D., et al. (2013). Dysferlin stabilizes stress-induced $\mathrm{Ca}^{2+}$ signaling in the transverse tubule membrane. Proc. Natl. Acad. Sci. U.S.A. 110, 20831-20836. doi: 10.1073/pnas.1307960110

Khairallah, R. J., Shi, G., Sbrana, F., Prosser, B. L., Borroto, C., Mazaitis, M. J., et al. (2012). Microtubules underlie dysfunction in Duchenne muscular dystrophy. Sci. Signal. 5, ra56. doi: 10.1126/scisignal.2002829

Klinge, L., Dean, A. F., Kress, W., Dixon, P., Charlton, R., Muller, J. S., et al. (2008). Late onset in dysferlinopathy widens the clinical spectrum. Neuromuscul. Disord. 18, 288-290. doi: 10.1016/j.nmd.2008.01.004

Kobayashi, K., Izawa, T., Kuwamura, M., and Yamate, J. (2010). The distribution and characterization of skeletal muscle lesions in dysferlin-deficient SJL and A/J mice. Exp. Toxicol. Pathol. 62, 509-517. doi: 10.1016/j.etp.2009.06.009

Kobayashi, K., Izawa, T., Kuwamura, M., and Yamate, J. (2011). Comparative gene expression analysis in the skeletal muscles of dysferlin-deficient SJL/J and A/J Mice. J. Toxicol. Pathol. 24, 49-62. doi: 10.1293/tox.24.49

Lennon, N. J., Kho, A., Bacskai, B. J., Perlmutter, S. L., Hyman, B. T., and Brown, R. H. Jr. (2003). Dysferlin interacts with annexins A1 and A2 and mediates sarcolemmal wound-healing. J. Biol. Chem. 278, 50466-50473. doi: 10.1074/jbc.M307247200

Malhotra, D., Thimmulappa, R., Navas-Acien, A., Sandford, A., Elliott, M., Singh, A., et al. (2008). Decline in Nrf2-regulated antioxidants in chronic obstructive pulmonary disease lungs due to loss of its positive regulator, DJ-1. Am. J. Respir. Crit. Care Med. 178, 592-604. doi: 10.1164/rccm.200803-380OC

Mendez, J., and Keys, A. (1960). Density and composition of mammalian muscle. Metabolism 9, 184-188.

Nemoto, H., Konno, S., Nakazora, H., Miura, H., and Kurihara, T. (2007) Histological and immunohistological changes of the skeletal muscles in older SJL/J mice. Eur. Neurol. 57, 19-25. doi: 10.1159/000097005

Ng, R., Banks, G. B., Hall, J. K., Muir, L. A., Ramos, J. N., Wicki, J., et al. (2012). Animal models of muscular dystrophy. Prog. Mol. Biol. Transl. Sci. 105, 83-111. doi: 10.1016/B978-0-12-394596-9.00004-4

Nguyen, K., Bassez, G., Bernard, R., Krahn, M., Labelle, V., Figarella-Branger, D., et al. (2005). Dysferlin mutations in LGMD2B, Miyoshi myopathy, and atypical dysferlinopathies. Hum. Mutat. 26, 165. doi: 10.1002/humu. 9355

Nigro, V. (2003). Molecular bases of autosomal recessive limb-girdle muscular dystrophies. Acta Myol. 22, 35-42.

Potgieter, M., Pretorius, E., Van der Merwe, C. F., Beukes, M., Vieira, W. A., Auer, R. E., et al. (2011). Histological assessment of SJL/J mice treated with the antioxidants coenzyme Q10 and resveratrol. Micron 42, 275-282. doi: 10.1016/j.micron.2010.10.001

Pratt, S. J., Lawlor, M. W., Shah, S. B., and Lovering, R. M. (2012). An in vivo rodent model of contraction-induced injury in the quadriceps muscle. Injury 43, 788-793. doi: 10.1016/j.injury.2011.09.015

Prosser, B. L., Khairallah, R. J., Ziman, A. P., Ward, C. W., and Lederer, W. J. (2013). X-ROS signaling in the heart and skeletal muscle: stretchdependent local ROS regulates $\left[\mathrm{Ca}^{2+}\right]$ i. J. Mol. Cell. Cardiol. 58, 172-81. doi: 10.1016/j.yjmcc.2012.11.011

Prosser, B. L., Ward, C. W., and Lederer, W. J. (2011). X-ROS signaling: rapid mechano-chemo transduction in heart. Science 333, 1440-1445. doi: 10.1126/science. 1202768

Rangasamy, T., Guo, J., Mitzner, W. A., Roman, J., Singh, A., Fryer, A. D., et al. (2005). Disruption of Nrf2 enhances susceptibility to severe airway inflammation and asthma in mice. J. Exp. Med. 202, 47-59. doi: 10.1084/jem. 20050538

Renjini, R., Gayathri, N., Nalini, A., and Srinivas Bharath, M. (2012). Oxidative damage in muscular dystrophy correlates with the severity of the pathology: role of glutathione metabolism. Neurochem. Res. 37, 885-898. doi: 10.1007/s11064011-0683-z

Safdar, A., DeBeer, J., and Tarnopolsky, M. (2010). Dysfunctional Nrf2-Keap1 redox signaling in skeletal muscle of the sedentary old. Free Radic. Biol. Med. 49, 1487-1493. doi: 10.1016/j.freeradbiomed.2010.08.010

Scheuerbrandt, G. (2008). Research approaches for a therapy of Duchenne muscular dystrophy. Parent Proj. Muscular Dystrophy 1-21. Available online at: http://www.duchenne-information.eu

Sharma, A., Yu, C., Leung, C., Trane, A., Lau, M., Utokaparch, S., et al. (2010). A new role for the muscle repair protein dysferlin in endothelial cell adhesion and angiogenesis. Arterioscler. Thromb. Vasc. Biol. 30, 2196-2204. doi: 10.1161/ATVBAHA.110.208108

Sussan, T., Rangasamy, T., Blake, D., Malhotra, D., El-Haddad, H., Bedja, D., et al. (2009). Targeting Nrf2 with the triterpenoid CDDO-imidazolide attenuates cigarette smoke induced emphysema and cardiac dysfunction in mice. Proc. Natl. Acad. Sci. U.S.A. 106, 250-255. doi: 10.1073/pnas.0804333106

Sykiotis, G., and Bohmann, D. (2010). Stress-activated cap'n'collar transcription factors in aging and human disease. Sci. Signal. 3, re3. doi: 10.1126/scisignal.3112re3

Terrill, J. R., Radley-Crabb, H. G., Iwasaki, T., Lemckert, F. A., Arthur, P. G., and Grounds, M. D. (2013). Oxidative stress and pathology in muscular dystrophies: focus on protein thiol oxidation and dysferlinopathies. FEBS J. 17, 4149-4164. doi: $10.1111 /$ febs. 12142

Thimmulappa, R. K., Fuchs, R., Malhotra, D., Scollick, C., Traore, K., Bream, J., et al. (2007). Preclinical evaluation of targeting the Nrf2 pathway by triterpenoids (CDDO-Im and CDDO-Me) for protection from LPS-induced inflammatory response and reactive oxygen species in human peripheral blod mononuclear cells and neutrophils. Antioxid. Redox Signal. 9, 1963-1970. doi: 10.1089/ars.2007.1745

Thimmulappa, R. K., Lee, H., Rangasamy, T., Reddy, S. P., Yamamoto, M., Kensler, T. W., et al. (2006). Nrf2 is a critical regulator of the innate immune response and survival during experimental sepsis. J. Clin. Invest. 116, 984-995. doi: 10.1172/JCI25790 
Turk, R., Sterrenburg, E., van der Wees, C. G., de Meijer, E. J., de Menezes, R. X., Groh, S., et al. (2006). Common pathological mechanisms in mouse models for muscular dystrophies. FASEB J. 20, 127-129. doi: 10.1096/fj.054678fje

Vainzof, M., Anderson, L. V., McNally, E. M., Davis, D. B., Faulkner, G., Valle, G., et al. (2001). Dysferlin protein analysis in limb-girdle muscular dystrophies. J. Mol. Neurosci. 17, 71-80. doi: 10.1385/JMN:17:1:71

Von der Hagen, M., Laval, S. H., Cree, L. M., Haldane, F., Pocock, M., Wappler, I., et al. (2005). The differential gene expression profiles of proximal and distal muscle groups are altered in pre-pathological dysferlindeficient mice. Neuromuscul. Disord. 15, 863-877. doi: 10.1016/j.nmd.2005. 09.002

Wang, J., Fields, J., Zhao, C., Langer, J., Thimmulappa, R. K., Kensler, T. W., et al. (2007). Role of Nrf2 in protection against intracerebral hemorrhage injury in mice. Free Radic. Biol. Med. 43, 408-414. doi: 10.1016/j.freeradbiomed.2007.04.020

Williams, J. H., Ward, C. W., Spangenburg, E. E., and Nelson, R. M. (1998). Functional aspects of skeletal muscle contractile apparatus and sarcoplasmic reticulum after fatigue. J. Appl. Physiol. 85, 619-626.

Ziman, A. P., Ward, C. W., Rodney, G. G., Lederer, W. J., and Bloch, R. J. (2010). Quantitative measurement of $\mathrm{Ca}^{2+}$ in the sarcoplasmic reticulum lumen of mammalian skeletal muscle. Biophys. J. 99, 2705-2714. doi: 10.1016/j.bpj.2010.08.032

Conflict of Interest Statement: The authors declare that the research was conducted in the absence of any commercial or financial relationships that could be construed as a potential conflict of interest.

Received: 09 December 2013; paper pending published: 04 January 2014; accepted: 29 January 2014; published online: 19 February 2014.

Citation: Kombairaju P, Kerr JP, Roche JA, Pratt SJP, Lovering RM, Sussan TE, Kim $J$-H, Shi G, Biswal S and Ward CW (2014) Genetic silencing of Nrf2 enhances X-ROS in dysferlin-deficient muscle. Front. Physiol. 5:57. doi: 10.3389/fphys.2014.00057

This article was submitted to Striated Muscle Physiology, a section of the journal Frontiers in Physiology.

Copyright (C) 2014 Kombairaju, Kerr, Roche, Pratt, Lovering, Sussan, Kim, Shi, Biswal and Ward. This is an open-access article distributed under the terms of the Creative Commons Attribution License (CC BY). The use, distribution or reproduction in other forums is permitted, provided the original author(s) or licensor are credited and that the original publication in this journal is cited, in accordance with accepted academic practice. No use, distribution or reproduction is permitted which does not comply with these terms. 